\title{
Are Pathogenic Leptospira a Possible Cause of Aseptic Meningitis in Suspected Children in Sudan?
}

\author{
Nada Abdelghani \\ Abdelrahim (D) \\ Imad Mohammed Fadl-Elmula ${ }^{2}$ \\ Rudy A Hartskeerl ${ }^{3}$ \\ Ahmed Ahmed ${ }^{3}$ \\ Marga Goris ${ }^{3}$ \\ 'Department of Medical Microbiology, \\ Faculty of Medical Laboratory Sciences, \\ Nile University, Khartoum, Sudan; \\ ${ }^{2}$ Department of Pathology \& Clinical \\ Genetics, Al-Neelain University and \\ Assafa Academy, Khartoum, Sudan; ${ }^{3} \mathrm{OIE}$ \\ and National Collaborating Centre for \\ Reference and Research on \\ Leptospirosis, Department of Medical \\ Microbiology, Academic Medical Center, \\ Amsterdam, Netherlands
}

\begin{abstract}
Introduction: Clinical presentations of leptospirosis are diverse, with meningitis easily confused with other microbial causes. We aimed to investigate the involvement of pathogenic leptospira in the cerebrospinal fluid (CSF) of meningitis-suspected children in Sudan.

Methods: A total of $153 \mathrm{CSF}$ specimens were collected over 5 months from patients attending a reference pediatric hospital in Omdurman, Sudan. All patients had provisionally been diagnosed with meningitis on admission. Demographic, clinical, and conventional laboratory findings were obtained. DNA was extracted using a QIAamp mini kit, and the $\sec Y$ gene investigated using real-time PCR.

Results: Nine of $153(6 \%)$ CSF specimens were positive for pathogenic leptospiral DNA. All these patients were male (seven infants and two toddlers aged $<4$ years). Typical conventional laboratory findings for aseptic meningitis (ie, CSF turbidity/pleocytosis, normal or reduced CSF glucose, normal or elevated proteins) were seen in five (56\%). All patients presented with fever and seizures, 56\% vomiting and stiff neck, and 29\% bulging fontanel. Most (67\%) patients presented in summer (March to May). Polymicrobial infections were identified in three patients $(33 \%)$.

Conclusion: We conclude that pathogenic leptospira are probably a common cause of meningitis in children in Sudan; therefore, we recommend including leptospirosis in the differential diagnosis of CNS infections and other undifferentiated febrile illnesses in this country.
\end{abstract}

Keywords: leptospirosis, infectious meningitis, PCR, pediatrics, Africa

\section{Introduction}

Although leptospirosis is one of the most widespread zoonotic diseases worldwide, ${ }^{1}$ it is widely underreported and there is a lack of sufficient systematic data from Africa. $^{2}$ Increases in incidence have been reported from countries where surveillance for leptospirosis is conducted, but unfortunately Sudan is not one of these countries. In a review by Allan et al, ${ }^{3}$ the only estimate of leptospirosis incidence in mainland Africa was from northern Tanzania, with regional incidence of 75-102 cases per 100,000 population per year. Preliminary data from Sudan suggest leptospirosis as a possible major public health problem. ${ }^{4}$ Indeed, conditions for maintenance of transmission cycles support the possibility of a high endemicity of leptospirosis in Sudan.

The clinical presentations of leptospirosis are diverse, ranging from undifferentiated fever to fulminant disease. ${ }^{5}$ Anicteric leptospirosis is the most common, occurring in $80 \%$ of cases. ${ }^{5}$ Leptospiral meningitis does occur, ${ }^{6,7}$ but is usually neglected or confused with other types of aseptic meningitis. ${ }^{8-11}$ Although
Correspondence: Nada Abdelghani Abdelrahim

Tel +24992275-1673

Email nada.ghani@hotmail.com 


\section{Graphical Abstract}

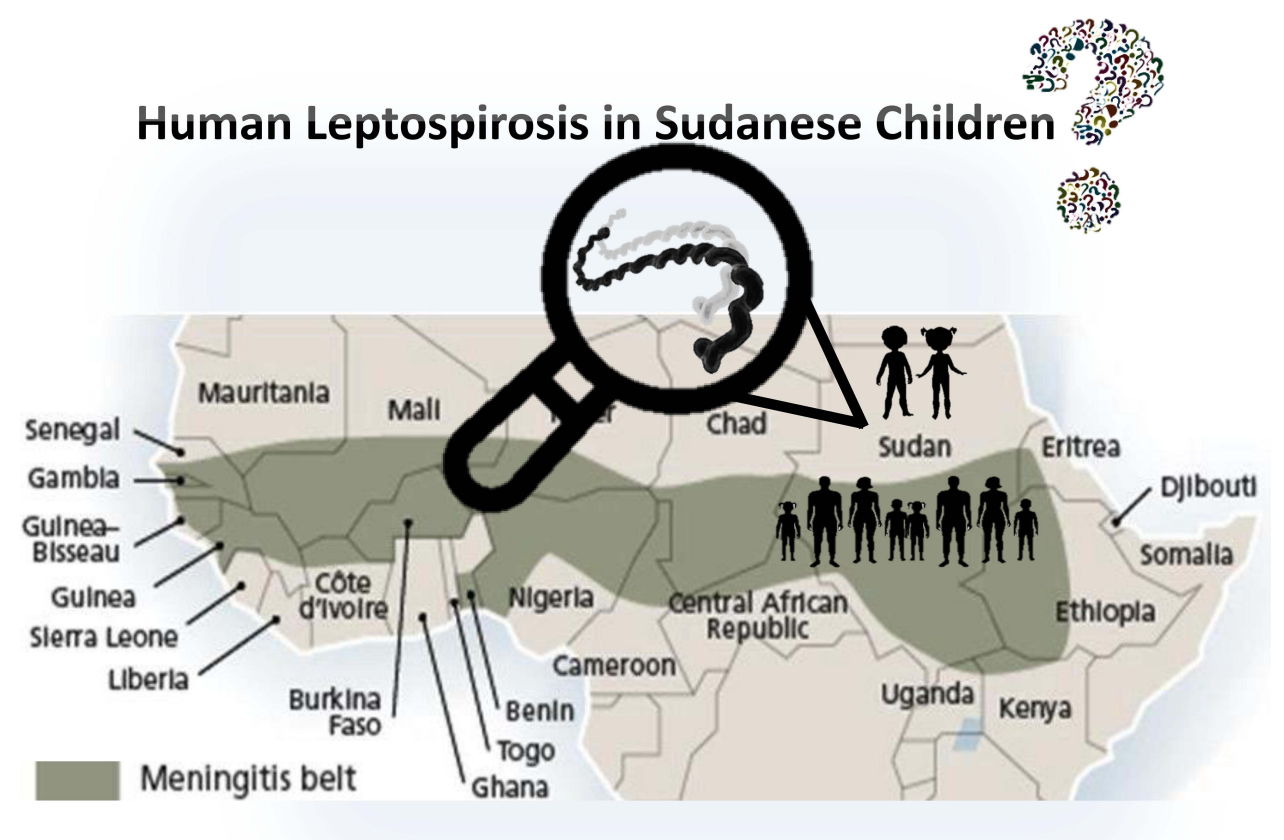

a majority of cases of leptospirosis are benign, ${ }^{12,13}$ the neurological forms can be fatal, ${ }^{14}$ some with a mortality rate of $26 \%{ }^{15}$ Sixteen case reports from Africa $^{3}$ have described acute leptospirosis in 34 individuals, where a wide range of clinical manifestations were reported, including fever, jaundice, acute respiratory distress syndrome, and meningitis. In Sudan, the occurrence and spread of leptospirosis and its meningeal forms are unknown.

Leptospirosis can be easily misdiagnosed because of symptoms that are also common in other infections and more prevalent here in Sudan. Headache in leptospirosis is often severe, resembling that occurring in dengue fever, ${ }^{1}$ with retro-orbital pain and photophobia that could be mistaken for bacterial meningitis. ${ }^{1}$ Interestingly, a 19-monthold boy was misdiagnosed with acute bacterial meningitis in Brazil and later proved to suffer from leptospiral meningitis and acute renal failure. ${ }^{8}$ The myalgia in leptospirosis is often intense, and affects the lower back, thighs, and calves, and together with fever could indicate malaria. ${ }^{1}$ The fever may be biphasic and recur after a remission of 3-4 days ${ }^{1}$ which may support suspicion of malaria. Data from northern Tanzania demonstrate the importance of leptospirosis, which accounts for $9 \%$ of febrile admissions ${ }^{16}$ compared to $1.6 \%$ of malaria in that area. ${ }^{17}$
In leptospirosis, abdominal pain, chills, and fever may suggest typhoid fever. ${ }^{1}$ In Sudan, typhoid-antibody titers are known to be elevated in the general healthy population. ${ }^{18}$ Infections like malaria, bacterial meningitis, or even dengue fever are also more common.

PCR is now a common diagnostic tool for the early and accurate diagnosis of microbial infections in clinical materials. $^{20-25}$ Unlike conventional assays, ${ }^{1,15,19}$ PCR can detect leptospiral DNA in cerebrospinal fluid (CSF) as soon as symptoms appear. Of 103 patients with meningitis of unknown origin in a study in Brazil, ${ }^{26} 40 \%$ were positive on PCR, whereas only $4 \%$ and $9 \%$ were positive on ELISA-IgM and MAT, respectively. In a later study in Brazil, $^{20}$ PCR identified leptospira in $59 \%$ of patients with aseptic meningitis, while MAT identified only 33\% and CSF culture none. Therefore, PCR has advantages over MAT and ELISA-IgM in the early diagnosis of leptospiral meningitis when antibodies are not present or are present at low levels in CSF.

To overcome all the diagnostic difficulties and reducefalse negative results, we used a well-developed and validated method ${ }^{21}$ that targets $\sec Y$ gene in pathogenic leptospira using SYBR green-based real-time PCR. This assay is claimed to have high diagnostic sensitivity (100\%, 95\% CI 70\%-100\%) and specificity (100\%, 95\% CI 93\%- 
$100 \%$ ) when compared with culture and serology as reference standards. The goal of the present study was to investigate the involvement of pathogenic leptospira in neuroinfections in bacterial meningitis-suspected febrile patients attending a major reference pediatric hospital in Omdurman/Khartoum, Sudan.

\section{Methods}

\section{Materials}

A total of 153 CSF specimens were collected from patients attending a major reference pediatric hospital in Omdurman, Sudan over 5 months (January to May 2010). These specimens were picked randomly from our stock of 503 (used in other studies). CSF volumes of $1.5-2 \mathrm{~mL}$ were immediately stored at $-80^{\circ} \mathrm{C}$ for nucleic acid investigations. All patients were children (age 0-14 years), and had been provisionally diagnosed with bacterial (septic) meningitis on admission. Demographic (age, sex), clinical (classic symptoms of meningeal irritation fever $>37^{\circ} \mathrm{C}$, headache, neck stiffness, vomiting, bulging fontanel, chills, seizures, altered mental status, coma, skin rash, petechiae, and photophobia) and conventional laboratory data (total white blood-cell count and type, glucose and protein concentrations, evidence of rapidly growing bacterial etiology) were obtained from hospital records. Patients were asked whether they had taken antibiotics during the week prior to lumbar puncture and if they had in close contact with individuals with similar symptoms.

\section{Ethics Approval and Consent to \\ Participate}

Ethics clearance for this study was obtained from the Ethics Committee Board of Al-Neelain University in September 2009. We were granted a waiver for informed/written consent, since patients were not contacted directly. Excess specimens were obtained from the hospital's main laboratory after all officially requested tests had been done. Clinical and demographic data were obtained from hospital files and kept anonymous at all stages of the study. Permission to collect remaining portions of the CSF specimens and clinical and demographic data was granted from hospital authorities (ie, hospital general director, laboratory senior supervisor, and the National Health Laboratory manager).

\section{Clinical Case Definition of Aseptic Meningitis}

Level 1 diagnostic certainty for aseptic meningitis was assigned for clinical evidence of acute meningitis (ie, fever $>37^{\circ} \mathrm{C}$, headache, vomiting, bulging fontanelle, nuchal rigidity, or other signs of meningeal irritation), CSF pleocytosis (five or more leukocytes/ $\mu \mathrm{L}$ if patient aged $\geq 2$ months or $>15$ leukocytes $/ \mu \mathrm{L}$ in infants aged $<2$ months), absence of any microorganisms on CSF Gram staining, and negative routine bacterial culture of CSF in the absence of antibiotic treatment before obtaining the first CSF specimen. ${ }^{27}$

\section{Nucleic Acid Investigations}

DNA was extracted from $200 \mu \mathrm{L}$ CSF specimens using a QIAamp DNA mini kit following the manufacturer's recommendations (Qiagen). Extracted total DNA was amplified using a DNA-binding SYBR green I dye technique with a CFX96 real-time system/C1000 thermal cycler (Bio-Rad Laboratories). Methods used for detecting pathogenic Leptospira spp. had been optimized and validated by the National Centre for Leptospirosis for use on human blood, urine, and kidney tissue. ${ }^{21}$

\section{Statistical Analysis}

Categorical variables are expressed in frequencies and percentages and numerical variables using measures of central tendency and dispersion. Statistically significant $(p \leq 0.05)$ differences and associations between variables and nucleic acid findings were assessed using Pearson's $\chi^{2}$ and Fisher's exact tests with SPSS 21.

\section{Results}

\section{Demographic Data}

All 153 patients investigated in this study were of low socioeconomic class and came from the suburbs, nearby villages, and areas surrounding the hospital in Omdurman city. Most admissions ( $\mathrm{n}=68,44.4 \%)$ and $67(43.8 \%)$ were in summer (March to June) and winter (January and February), respectively. There were 99 (64.7\%) male patients. Median age was 1.5 years (range 25 days to 15 years, ie, 0.07-15 years). Median age among male patients was 1.5 (IQR 1.75, 0.07-15, $\mathrm{n}=95$ [four missing]) years and among female patients 1.5 (IQR 1.5, 0.25-11, $\mathrm{n}=54)$ years. A majority were aged $1-5$ years $(\mathrm{n}=91$, $59.5 \%$ ), followed by those aged $\leq 11$ months ( $\mathrm{n}=51$, $33.4 \%$ ) of 149 cases (four [2.6\%] missing). 


\section{Clinical Data}

A vast majority of cases with full clinical records $(n=111$, $72.5 \%$ [42 missing]) presented with fever $(n=110,71.9 \%)$ and seizures $(n=101,66 \%)$. Other common symptoms were vomiting $(n=53,34.6 \%)$, chills $(n=22,14.4 \%)$, stiff neck $(n=9,5.9 \%)$, and altered mental status $(n=9,17.7 \%)$. Among 1-year-olds and above, headache was detected in seven of 72 (9.7\%), with 32 (44.4\%) inconclusive. Among the 51 infants aged $<1$ year, bulging fontanelle was detected in nine $(5.9 \%)$. None of the 111 patients had come in close contact with family members or relatives with similar symptoms, received any type of antibiotics before hospital admission, or suffered complications during hospitalization, and were thus discharged. A total of 72 (64.9\%) were diagnosed with a CNS-associated condition: $67(60.4 \%)$ bacterial (septic) meningitis, one (0.9\%) brain abscess, and four (3.6\%) febrile convulsions. The remaining $39(35.1 \%)$ were diagnosed with other infections. All patients were treated during hospitalization with first-line and/or second-line antibiotic therapies.

\section{Conventional Laboratory Data}

A total of 16 of the $153(10.5 \%)$ patients had traumatic CSF specimens; therefore, cytological and chemical analyses were not performed. A vast majority (92.1\%, 105 of 114 [39 $\{25.5 \%\}$ missing cell counts]) of CSF specimens that were atraumatic showed normal CSF WBC levels ( $<$ five cells $/ \mathrm{mm}^{3}$ ). CSF pleocytosis - 50 to 26,000 cells/ $\mathrm{mm}^{3}$ - was detected in the remaining nine (7.9\%) specimens: six turbid, one clear, and two bloody. Abnormal CSF-glucose concentration $(<45$ or $>100 \mathrm{mg} / \mathrm{dL})$ was seen in $14.1 \%$ (19 of 135 [18 missing]). Abnormal CSFprotein concentration $(<14$ or $>45 \mathrm{mg} / \mathrm{dL})$ was seen in $49.6 \%$ (67 of 135 [18 missing]). Direct Gram-stain preparation showed Gram-positive cocci in clusters in $1.5 \%$ (two of 133 [20 missing]) and Gram-negative diplococci in another $1.5 \%$. On CSF culture for rapidly growing bacteria, all specimens that were Gram-positive were identified as $S$. pneumoniae $(1.5 \%, \mathrm{n}=2)$ and all those that were Gram negative as $N$. meningitidis $(1.5 \%, \mathrm{n}=2)$.

\section{PCR Findings}

Of the 153 PCR-tested CSF specimens, nine (6\%) were found to be positive for pathogenic leptospiral DNA ( $\sec Y$ gene), with Tm of 79.5-82.0. PCR findings for individual cases are shown in Table 1.
Table I Ct and Tm for CSF Specimens with Positive Pathogenic Leptospiral DNA (SecY gene) Using SYBR Green Method on Qualitative Real-Time PCR

\begin{tabular}{|l|c|c|}
\hline Sample & Ct & Tm \\
\hline$I$ & 39.5 & 81 \\
\hline 2 & 38 & 80 \\
\hline 3 & 36.9 & 82 \\
\hline 4 & 39 & 79.5 \\
\hline 5 & 38.5 & 80.5 \\
\hline 6 & 39 & 80.5 \\
\hline 7 & 39 & 81 \\
\hline 8 & 39 & 80 \\
\hline 9 & 38.5 & 80 \\
\hline
\end{tabular}

\section{Findings on Patients with Positive PCR for Pathogenic Leptospiral DNA}

Most leptospira-positive patients (seven of nine, 77.8\%) were aged $<1$ year (average $5 \pm 2$ months, range $3-8$ months). The remaining two were toddlers aged 1.2 and 4 years. All nine $(100 \%)$ were male patients, most (six of nine, 66.7\%) admitted to hospital in summer (March to May), and the remaining in winter (January and February). All nine (100\%) patients reported no antibiotic use prior to admission and CSF-specimen collection. They had not received any vaccinations or come in close contact with individuals presenting symptoms of meningitis or other febrile illness. All patients $(9 / 9,100 \%)$ presented with fever and seizures, most (six of nine, 66.7\%) with vomiting, while stiff neck and chills were less frequently observed (Table 2). Bulging fontanel was seen in two of the seven infants (28.6\%). Other symptoms/signs like headache, skin rash, petechiae, photophobia, altered mental status, and coma were not observed.

Two (22.2\%) CSF specimens were traumatic and thus CSF-cell count and glucose and protein concentrations were not estimated. Most remaining specimens (four of six, $66.7 \%$ [one missing]) were turbid, showing leukocytosis of $1,300-26,000$ cells $/ \mathrm{mm}^{3}$ with neutrophil predominance (up to $70 \%$ ). CSF-glucose concentration was low in three $(50 \%)-10-29 \mathrm{mg} / \mathrm{dL}$. Most (four of six, 66.7\%) CSF specimens were high in protein concentration $183-875 \mathrm{mg} / \mathrm{dL}$ (Table 2). All CSF specimens that were turbid and had leukocytosis were high in protein 
Table 2 Demographic, Clinical, and Conventional Laboratory Data for Cases with Positive Pathogenic Leptospiral DNA (SecY gene)

\begin{tabular}{|c|c|c|}
\hline \multicolumn{2}{|c|}{ Demographic data $(n=9)$} & \multirow{2}{*}{$\begin{array}{c}\text { n (\%) } \\
9(100)\end{array}$} \\
\hline Sex & Male & \\
\hline & Female & 0 \\
\hline \multirow[t]{2}{*}{ Age-group } & $<12$ months & $7(77.8)$ \\
\hline & $\mathrm{I}-4$ years & $2(22.2)$ \\
\hline \multirow[t]{2}{*}{ Season of admission } & Winter (January-February) & $3(33.3)$ \\
\hline & Summer (March-May) & $6(66.7)$ \\
\hline \multicolumn{2}{|c|}{ Signs and symptoms ${ }^{a}(n=9)$} & \\
\hline \multicolumn{2}{|l|}{ Fever } & $9(100)$ \\
\hline \multicolumn{2}{|l|}{ Seizures } & $8(88.9)$ \\
\hline \multicolumn{2}{|l|}{ Vomiting } & $6(66.7)$ \\
\hline \multicolumn{2}{|l|}{ Chills } & $\mathrm{I}(\mathrm{II} . \mathrm{I})$ \\
\hline \multicolumn{2}{|l|}{ Stiff neck } & $4(44.4)$ \\
\hline \multicolumn{2}{|c|}{ Conventional lab results $(n=6)^{b}$} & \\
\hline \multirow[t]{2}{*}{ CSF WBC count } & Normal $\left(<5\right.$ cells $\left./ \mathrm{mm}^{3}\right)$ & $2(33.3)$ \\
\hline & High $\left(>1,000\right.$ cells $\left./ \mathrm{mm}^{3}\right)$ & $4(66.7)$ \\
\hline \multirow[t]{2}{*}{ CSF glucose level } & Normal (45-100 mg/dL) & $3(50)$ \\
\hline & Low $(<45 \mathrm{mg} / \mathrm{dL})$ & $3(50)$ \\
\hline \multirow[t]{3}{*}{ CSF protein level } & Normal (14-45 mg/dL) & I (I6.7) \\
\hline & High (> 45 mg/dL) & $4(66.7)$ \\
\hline & Low $(<14$ mg/dL) & I (16.7) \\
\hline
\end{tabular}

Notes: ${ }^{a} O$ ther signs and symptoms of meningeal irritation (headache for $>1$-year-olds, skin rash, petechiae, photophobia, altered mental status, and coma) were investigated, but not found; ${ }^{b}$ Two (22.2\%) of the nine CSF specimens were traumatic; therefore, CSF cell count and glucose and protein concentrations were not estimated. Data for one case were missing.

concentration (four of four), and most (three of four, 75\%) were low in glucose concentration. The specimen with the highest WBC count $\left(26,000\right.$ cells $\left./ \mathrm{mm}^{3}\right)$ was also positive for Streptococcus pneumoniae. All remaining specimens (eight of nine, $88.9 \%$ ) were negative for routinely tested rapidly growing bacteria. Nevertheless, most (seven of nine, $77.8 \%$ ) cases were diagnosed with bacterial meningitis on discharge. All patients were administered antibiotics during hospitalization, recovered, and were discharged. All findings on individual cases are detailed in Supplementary Table 1. The final classification of cases based on clinical and nucleic acid findings is shown in Table 3.
Table 3 Classification of Cases Based on Clinical and Nucleic Acid Findings

\begin{tabular}{|l|c|c|c|}
\hline & \multicolumn{2}{|c|}{ Cases, $\mathbf{n = 1 5 3 ^ { \mathbf { a } }}$} & \multirow{2}{*}{$\%, \mathbf{n}=16^{\mathbf{b}}$} \\
\cline { 2 - 3 } & $\%$ & $\mathbf{n}$ & \\
\hline Proven infectious meningitis $^{\mathbf{c}}$ & 10.5 & $16^{\mathrm{b}}$ & 100 \\
\hline Proven aseptic meningitis $^{\mathrm{d}}$ & 8.5 & $13^{\mathrm{e}}$ & 81.3 \\
\hline Leptospiral meningitis $^{*}$ & 5.9 & 9 & 56.3 \\
\hline
\end{tabular}

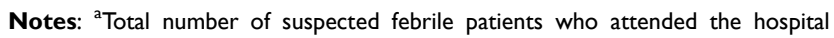
during the study period and were subjected to LP; bum of seven cases with positive microbial origins but normal cellular count and nine with CSF pleocytosis with or without positive microbial etiology; ' part of this information has been shared in our previous publication; ${ }^{28}$ part of this information has been shared in our previous publication; ${ }^{29}$ ethe 16 cases with proven infectious meningitis minus the three with positive bacterial culture (the fourth case had mixed infection: Streptococcus pneumoniae and leptospira).

\section{Discussion}

Pathogenic leptospiral DNA ( $\sec Y$ gene) was successfully identified in nine randomly selected CSF specimens from meningitis-suspected attendees of a major reference pediatric hospital in Omdurman, Khartoum, Sudan from January to May 2010. Consequently, human leptospiral infection does exist in Sudan, with the neurological form reaching a proportion of $6 \%$. Studies in the $1950 \mathrm{~s}^{30-32}$ reported that leptospira may account for a significant minority of all causes of aseptic meningitis. However, in 1995 Farr ${ }^{33}$ reported higher estimates of $\sim 10 \%$ and in 1998 Abraham $^{34}$ reported $5 \%-13 \%$ of all cases of aseptic meningitis were caused by leptospira. In a large systematic review by Allan et $\mathrm{al}^{3}$ of 46 studies from 26 African countries between 1930 and the end of 2014, the prevalence of acute human leptospirosis ranged from $2.3 \%$ to $19.8 \%$ in hospitalized patients with aspecific febrile illness. Our finding of $6 \%$ among randomly selected febrile meningitis-suspected patients concurs. However, when using properly identified groups (reported in our previous publications), ${ }^{28,29}$ our estimate is dramatically increased: $56 \%$ of 16 cases with proven infectious meningitis ${ }^{28}$ and $69 \%$ of 13 cases with proven aseptic meningitis (Table 3). ${ }^{29}$ These estimates coincide with those obtained from later and recent studies. A study from Brazil in $1998^{26}$ identified pathogenic leptospira in CSF by PCR in $40 \%$ (41 of 103) of patients with aseptic meningitis, while a later study in 2010 by the same researchers ${ }^{20}$ found a higher proportion of 59\% (23 of 39).

Leptospiral meningitis is a disease of young people. $^{30,35}$ In their 1958 series of 616 cases, Alston and Broom noted that $62 \%$ of children aged $\leq 14$ years 
presented with aseptic meningitis caused by leptospira. ${ }^{42}$ In Romero et al's $1998^{26}$ study, patients were aged 0-60 years; however, $46 \%$ of the positive results were observed in patients aged $<10$ years. In Romero et al's 2010 study, ${ }^{20}$ $31 \%$ of patients with leptospiral meningitis were aged 319 years, of which $80 \%$ were male. Interestingly, we also found male predominance (100\%) among our confirmed leptospiral meningitis patients, and of course all were children: $78 \%$ aged $<1$ year and the remaining aged $1-4$ years. Several case reports have found leptospiral meningitis with or without acute renal failure in male patients but at different young ages: in an infant, ${ }^{26}$ a toddler, ${ }^{8}$ and a teen. ${ }^{36}$

Leptospirosis is presumed to be the most widespread zoonosis in the world. ${ }^{2}$ Incidence is significantly higher in the warm climates of tropical and subtropical countries. $^{37,38}$ In Sudan, as most African countries with similar climatogeographic conditions, leptospirosis remains an unknown health problem. Most of the little information in the literature from Africa is provided in the form of case reports of confirmed or probable acute leptospirosis in countries like South Africa $(n=6)$, Gabon $(\mathrm{n}=3)$, Morocco $(\mathrm{n}=3)$, Algeria $(\mathrm{n}=1)$, Mali $(\mathrm{n}=1)$, Réunion $(\mathrm{n}=1)$, and Senegal $(\mathrm{n}=1){ }^{3}$

All cases that were identified as having leptospiral meningitis in our study were treated with antibiotics during hospitalization, as they were thought to suffer from bacterial meningitis or respiratory infections. Despite the incorrect diagnoses, treatment with penicillin, ampicillin, cephalosporin, and/or chloramphenicol actually helped these patients. According to Katz et al, ${ }^{39}$ antimicrobial treatment benefits leptospirosis patients, leading to decreased illness duration and complication severity. A clinical study demonstrated that ceftriaxone and penicillin $G$ were equally effective treatments for severe leptospirosis. ${ }^{40}$

Signs of meningeal irritation are uncommon in the leptospiremic phase, which occurs within the first 5-7 days of symptom onset. ${ }^{34}$ In this study, fever (100\%) and seizures (75\%) predominated, vomiting (63\%) was observed in most cases, while stiff neck (38\%) and bulging fontanel $(29 \%)$ were detected in a few. Leptospira can be isolated in this phase from CSF while cytology and biochemistry are usually normal. ${ }^{34}$ Among our cases with positive CSF leptospiral DNA, only one (11\%) showed normal CSF parameters. Following the leptospiremic phase is the immune phase, which is mediated by immunocomplexes and characterized by the classical manifestation of headache, vomiting, and meningeal irritation. ${ }^{1,34}$ Most of our patients manifested these symptoms, excluding headache. Abraham ${ }^{34}$ reported that only half their leptospiral meningitis patients had clinical features. In the immune phase, CSF shows normal glucose levels, raised proteins, and lymphocytic pleocytosis. ${ }^{1,34}$ In this study, two-thirds of patients demonstrated low glucose and high proteins, and the pleocytosis was predominantly neutrophilic. Levett ${ }^{1}$ stated that CSF abnormalities were common. A third of our patients showed normal CSF WBCs, normal CSF glucose, and normal or low CSF proteins. The CSF of one of our proven leptospiral meningitis patients was also positive for $S$. pneumoniae, ${ }^{28}$ while those of the other two were positive for HHV6. ${ }^{29}$ Overlapping infections among leptospirosis patients have been frequently reported. ${ }^{41}$

It is worth mentioning that this specific major referral pediatric hospital takes part in the Bacterial Meningitis Program, which is funded by the WHO and supported by the Sudanese Ministry of Health. Collection and maintainenance of good-quality demographic, clinical, and conventional laboratory data are ensured. However, specific information on exposure and risks of zoonotic infections (eg, leptospirosis) are not obtained, and we were thus limited by this shortage in data. Also, PCR is still an expensive tool to use in this part of the world. We could not perform PCR-based tests for leptospirosis in a larger sample.

\section{Conclusion}

We conclude that pathogenic leptospira is probably a common CNS pathogen affecting children in Sudan. Therefore, we recommend including leptospirosis in the differential diagnosis of CNS infections and other febrile illness of unknown etiology in this country.

\section{Data Sharing}

The data sets used and/or analyzed during the current study will be available from the corresponding author on reasonable request.

\section{Consent for Publication}

All authors consented to the publication of this article.

\section{Acknowledgments}

We acknowledge all laboratory technologists in the bacteriology departments of the Omdurman Hospital for Children, the National Health Laboratory, and the central 
public laboratories of the Ministry of Health for providing clinical data and specimens. We also thank the administrations of the Sudan Medical and Scientific Research Institute (SUMASRI) of the University of Medical Sciences and Technology (UMST) in Khartoum, Sudan for providing working space and allowing use of laboratory ware. We are indebted for the kind gesture of a complete bench-fee waiver that was provided by the OIE and the National Collaborating Centre for Reference and Research on Leptospirosis, Department of Medical Microbiology, Academic Medical Center, Amsterdam, Netherlands to perform all molecular investigations.

\section{Author Contributions}

All authors made a significant contribution to the work reported, whether in conception, study design, execution, acquisition of data, analysis, and interpretation, or all these areas, took part in drafting, revising, or critically reviewing the article, gave final approval to the version to be published, have agreed on the journal to which the article has been submitted, and agree to be accountable for all aspects of the work.

\section{Funding}

Molecular laboratory investigations were fully funded by the OIE and National Collaborating Centre for Reference and Research on Leptospirosis, Department of Medical Microbiology, Academic Medical Center, Amsterdam, Netherlands.

\section{Disclosure}

The authors report no competing interests with respect to the research, authorship, and/or publication of this article.

\section{References}

1. Levett PN. Leptospirosis. Clin Microbiol Rev. 2001;14(2):296-326. doi:10.1128/CMR.14.2.296-326.2001

2. World Health Organization-LERG. Report of the First Meeting of the Leptospirosis Burden Epidemiology Reference Group. Geneva: World Health Organization; 2010.

3. Allan KJ, Biggs HM, Halliday JEB, et al. Epidemiology of leptospirosis in Africa: a systematic review of a neglected zoonosis and a paradigm for 'One Health' in Africa. PLoS Negl Trop Dis. 2015;9 (9):e0003899. doi:10.1371/journal.pntd.0003899

4. Mossaad EE, Strutz F. The Prevalence of Leptospirosis in Patients with End-Stage Renal Failure in Sudan, in Bacterial, Waterborne and Emerging Infectious Diseases in North Africa and the Middle East. Nicosia, Cyprus: National Institute of Allergy and Infectious Diseases (NIAID); 2011.
5. Faucher JF, Hoen B, Estavoyer JM. The management of leptospirosis. Expert Opin Pharmacother. 2004;5(4):819-827. doi:10.1517/1465 6566.5.4.819

6. Sperber SJ, Schleupner CJ. Leptospirosis: a forgotten cause of aseptic meningitis and multisystem febrile illness. South Med J. 1989;82 (10): 1285-1288.

7. Gollop JH, Pang L, Sasaki DM. Leptospirosis: a possible cause of "aseptic meningitis". Hawaii Med J. 1990;49(5):162, 165.

8. de Souza AL, Sztajnbok J, Marques SR, et al. Leptospirosis-induced meningitis and acute renal failure in a 19-month-old male child. J Med Microbiol. 2006;55(6):795-797. doi:10.1099/jmm.0.46486-0

9. Merwick A, Kelly S, Galvin R. Meningitis due to leptospiria hardjoidentifying a treatable cause of aseptic lymphocytic meningitis. Ir Med J. 2008;101(3):91.

10. Nelsen S, Sealy DP, Schneider EF. The aseptic meningitis syndrome. Am Fam Physician. 1993;48(5):809-815.

11. de Almeida SM, Nogueira MB, Raboni SM, et al. Laboratorial diagnosis of lymphocytic meningitis. Braz J Infect Dis. 2007;11 (5):489-495. doi:10.1590/S1413-86702007000500010

12. Beeson PB, Hankey DD. "Benign aseptic meningitis" as a manifestation of leptospiral infection. Trans Assoc Am Physicians. 1950;63:130-135.

13. Bigham RS Jr. Benign aseptic meningitis due to Leptospira grippotyphosa; second report of clinical infection in the United States. AMA Arch Intern Med. 1953;92(4):587-590. doi:10.1001/ archinte. 1953.00240220135016

14. Kitaoka M, Hyakutare S, Mori M. Identification of Leptospira andamana isolated from the spinal fluid of a fatal case of leptospirosis in Sao Paulo, 1963. J Hyg Epidemiol Microbiol Immunol. 1976;20 (4):437-442.

15. Mathew T, Satishchandra P, Mahadevan A, et al. Neuroleptospirosisrevisited: experience from a tertiary care neurological centre from south India. Indian J Med Res. 2006;124(2):155-162.

16. Biggs HM, Shadomy SV, Crump JA, et al. Leptospirosis among hospitalized febrile patients in northern Tanzania. Am J Trop Med Hyg. 2011;85(2):275-281. doi:10.4269/ajtmh.2011.11-0176

17. Crump JA, Ramadhani HO, Morrissey AB, et al. Invasive bacterial and fungal infections among hospitalized HIV-infected and HIV-uninfected adults and adolescents in northern Tanzania. Clin Infect Dis. 2011;52(3):341-348. doi:10.1093/cid/ciq103

18. El-Shafie S. The Widal test in a normal healthy population in the Sudan. East Afr Med J. 1991;68(4):266-269. PMID: 1914976.

19. Sakata EE, Yasuda PH, Romero EC, et al. The serovars of Leptospira interrogans isolated from cases of human leptospirosis in Sao Paulo, Brazil. Rev Inst Med Trop Sao Paulo. 1992;34(3):217-221. doi:10.1590/S0036-46651992000300006

20. Romero EC, Blanco RM, Yasuda PH. Aseptic meningitis caused by Leptospira spp diagnosed by polymerase chain reaction. Mem Inst Oswaldo Cruz. 2010;105(8):988-992. doi:10.1590/S0074-0276201 0000800007

21. Ahmed A, Engelberts MF, Boer KR, et al. Development and validation of a real-time PCR for detection of pathogenic leptospira species in clinical materials. PLoS One. 2009;4(9):e7093. doi:10.1371/journal.pone. 0007093

22. Margall CN, Moreno MM, Otín CL, et al. Use of universal PCR on cerebrospinal fluid to diagnose bacterial meningitis in culture-negative patients. Eur J Clin Microbiol Infect Dis. 2002;21 (1):67-69. doi:10.1007/s10096-001-0656-2

23. Saravolatz LD, Manzor O, VanderVelde N, et al. Broad-range bacterial polymerase chain reaction for early detection of bacterial meningitis. Clin Infect Dis. 2003;36(1):40-45. doi:10.1086/345438

24. Avery RA, Frank G, Eppes SC. Diagnostic utility of Borrelia burgdorferi cerebrospinal fluid polymerase chain reaction in children with Lyme meningitis. Pediatr Infect Dis J. 2005;24(8):705-708. doi:10.1097/01.inf.0000172903.14077.4c 
25. Zambrano Y, Chiarello A, Soca A, et al. Use of polymerase chain reaction for the diagnosis of central nervous system infections. Invest Clin. 2006;47(4):337-347.

26. Romero EC, Billerbeck AE, Lando VS, et al. Detection of Leptospira DNA in patients with aseptic meningitis by PCR. J Clin Microbiol. 1998;36(5):1453-1455. doi:10.1128/JCM.36.5.1453-1455.1998

27. Tapiainen T, Prevots R, Izurieta HS, et al. Aseptic meningitis: case definition and guidelines for collection, analysis and presentation of immunization safety data. Vaccine. 2007;25(31):5793-5802. doi:10. 1016/j.vaccine.2007.04.058

28. Abdelrahim NA, Fadl-Elmula IM, Ali HM. Bacterial meningitis in Sudanese children; critical evaluation of the clinical decision using clinical prediction rules. BMC Pediatr. 2019;19(1):319. doi:10.1186/ s12887-019-1684-3

29. Abdelrahim NA, Mohammed N, Evander M, Ahlm C, Fadl-Elmula IM. Human herpes virus type 6 is associated with CNS infections in children in Sudan. A J Lab Med. 2021. (Submitted). doi:10.21203/rs.3.rs-127726/v1

30. Beeson PB, Hankey DD. Leptospiral meningitis. AMA Arch Intern Med. 1952;89(4):575-583. doi:10.1001/archinte.1952.00240040054007

31. Gauld RL, Crouch WL, Kaminsky AL, et al. Leptospiral meningitis: report of outbreak among American troops on Okinawa. J Am Med Assoc. 1952;149(3):229-231. doi:10.1001/jama.1952.02930200014004

32. Fox EG, Fyfe WM. Leptospiral meningitis: report of a case. Glasgow Med J. 1951;32(10):311-312.

33. Farr RW. Leptospirosis. Clin Infect Dis. 1995;21(1):1-6. doi:10.1093/ clinids/21.1.1

34. Abraham M. The central nervous system in leptospirosis. Kerala Med J. 1998;38:21-23.
35. King SD, Urquhart AE. Laboratory investigations on four cases of leptospiral meningitis in Jamaica. West Indian Med J. 1975;24 (4):196-201.

36. Karande S, Patil S, Kulkarni M, et al. Acute aseptic meningitis as the only presenting feature of leptospirosis. Pediatr Infect Dis J. 2005;24(4):390-391. doi:10.1097/01.inf.0000157351.44089.7e

37. Zunino ME, Pizarro PR. Leptospirosis: a literature review. Rev Chilena Infectol. 2007;24(3):220-226. doi:10.4067/s0716-101820070 00300008

38. Natarajaseenivasan K, Prabhu N, Selvanayaki K, et al. Human leptospirosis in Erode, South India: serology, isolation, and characterization of the isolates by randomly amplified polymorphic DNA (RAPD) fingerprinting. Jpn J Infect Dis. 2004;57(5): 193-197.

39. Katz AR, Ansdell VE, Effler PV, et al. Assessment of the clinical presentation and treatment of 353 cases of laboratory-confirmed leptospirosis in Hawaii, 1974-1998. Clin Infect Dis. 2001;33 (11):1834-1841. doi:10.1086/324084

40. Panaphut T, Domrongkitchaiporn S, Vibhagool A, et al. Ceftriaxone compared with sodium penicillin $\mathrm{g}$ for treatment of severe leptospirosis. Clin Infect Dis. 2003;36(12):1507-1513. doi:10.1086/ 375226

41. Rajajee S, Shankar J, Dhattatri L. Pediatric presentations of leptospirosis. Indian J Pediatr. 2002;69(10):851-853. doi:10.1007/ BF02723704

42. Alston JM, Broom JC. Leptospirosis in man and animals. E. \& S. Edinburgh, U.K: Livingstone;. 1998:198
Research and Reports in Tropical Medicine

\section{Publish your work in this journal}

Research and Reports in Tropical Medicine is an international, peerreviewed, open access journal publishing original research, case reports, editorials, reviews and commentaries on all areas of tropical medicine, including: Diseases and medicine in tropical regions; Entomology; Epidemiology; Health economics issues; Infectious disease; Laboratory science and new technology in tropical medicine;

\section{Dovepress}

Parasitology; Public health medicine/health care policy in tropical regions; and Microbiology. The manuscript management system is completely online and includes a very quick and fair peer-review system. Visit http://www.dovepress.com/testimonials.php to read real quotes from published authors. 